\title{
A ASSISTÊNCIA À DOENÇA NO ALTO MINHO OITOCENTISTA: O CASO DO HOSPITAL DE NOSSA SENHORA DA VISITAÇÃO DE CAMINHA
}

\author{
Alexandra Esteves \\ Universidade Católica Portuguesa e Investigadora do Lab2PT, Instituto de Ciências Sociais, Universidade do Minho \\ estevesalexandra@gmail.com
}

Recibido: 23 febrero 2014; Aceptado: 10 junio 2014.

\begin{abstract}
Cómo citar este artículo/Citation: Esteves, Alexandra (2015), "A assistência à doença no Alto Minho oitocentista: o caso do hospital de Nossa Senhora da Visitação de Caminha”, Asclepio 67 (1): p083. doi: http://dx.doi.org/10.3989/asclepio.2015.09

RESUMO: O presente trabalho tem como objetivo analisar o papel desempenhado pelo hospital da Misericórdia de Caminha na assistência à doença, durante o século XIX. Nesse sentido, através da atividade desenvolvida por esta instituição e pelos profissionais que nela trabalhavam, procuraremos conhecer as respostas que então eram proporcionadas no âmbito da prestação de cuidados de saúde à população. Temos ainda como objetivo evidenciar as particularidades que caracterizavam o quotidiano daquela unidade hospitalar, considerando os doentes que a procuravam e as enfermidades de que padeciam e tendo ainda presente o contexto económico e social que, na centúria de oitocentos, marcava a vila alto minhota de Caminha.
\end{abstract}

PALAVRAS-CHAVE: Hospital; Misericórdia; Caminha, Doentes; Enfermidades.

\section{THE ASSISTANCE TO THE DISEASE IN THE ALTO MINHO OF THE NINETEENTH CENTURY: THE CASE OF THE NOSSA SENHORA DA VISITAÇÃO HOSPITAL OF CAMINHA}

ABSTRACT: This study aims to analyze the role played, in care of illness, by the hospital of the Misericórdia of Caminha during the nineteenth century. Through the action of this institution and the professionals who worked on it, we will try to know the answers within the framework of existing health care in this village in northern Portugal. We also aim to highlight the peculiarities that characterized the hospital daily life of this institution, analyzing those who sought and the diseases which affected them, always intending to establish a relationship with the economic and social context that marked this village of the Alto Minho region in the $19^{\text {th }}$ century.

KEY WORDS: Hospital; Misercórdia; Caminha; Patients, Diseases. 


\section{INTRODUÇÃO}

O estudo das instituições, nas suas diversas vertentes, permite descobrir muitos dos problemas das sociedades passadas e contemporâneas, bem como identificar os procedimentos adotados com vista à sua resolução. É o que acontece, por exemplo, no domínio da saúde. O estudo dos hospitais representa um contributo fundamental para a compreensão da atitude da sociedade face à doença e aos doentes, além de proporcionar informação acerca da incidência das diversas enfermidades e as formas de tratamento. Um conhecimento mais aprofundado sobre estes assuntos só poderá ser alcançado através de análises comparativas e inter-regionais. No entanto, uma investigação mais micro, focalizada numa determinada unidade hospitalar, pode satisfazer outras pretensões, tais como descobrir a sua área de intervenção, conhecer os seus utentes e as razões que os levavam a procurar os seus serviços, além de permitir a colocação de questões mais abrangentes que se inscrevem no domínio do social e da saúde pública.

O nosso trabalho centra-se no hospital de Caminha, vila situada no distrito de Viana do Castelo, junto à fronteira com a província espanhola da Galiza ${ }^{1}$. Tratase de uma pequena unidade hospitalar, destinada a receber doentes pobres de ambos os sexos, cuja fundação remonta ao século XV e que foi integrada na Santa Casa da Misericórdia da vila em 1516 (Esteves, 2011, pp. 201-2012; Araújo, 2005, pp. 668-669). Em oitocentos, anexo ao hospital, existia um banco onde, diariamente, eram feitos pequenos curativos, que para os pobres eram gratuitos ${ }^{2}$. Além do internamento e tratamento, a instituição prestava ainda apoio domiciliário aos enfermos, sempre que tal se justificava ${ }^{3}$.

No século XIX, tirando o período compreendido entre 1856 e 1862, para o qual não dispomos de informação, esta unidade hospitalar assistiu, entre 1840 e 1878, um total de 1056 doentes, sendo 537 homens e 511 mulheres, se bem que em alguns casos não era mencionado o sexo dos pacientes ${ }^{4}$. Esta proximidade dos números demonstra que os elementos do sexo feminino não tinham qualquer pejo em recorrer aos serviços hospitalares, ao contrário do que acontecia noutras regiões do país, onde a elevada afluência de homens levaria certamente muitas mulheres, por uma questão de pudor, a optarem pelo tratamento no recato do lar (Araújo, 2010; Lopes, 2000, pp. 679-630).

O ritmo de entradas conheceu variações, determinadas certamente pelas vicissitudes que afetaram a região e que marcaram a vida do concelho e do distrito de Viana do Castelo nestes anos da centúria de oitocentos. Os anos de 1848 e 1849 foram os que registaram um maior número de ingressos: 98 e 99 doentes, respetivamente. Nesse período, ressalta a entrada de homens e mulheres que, genericamente, eram qualificados como pobres, tendo sido adotada uma nomenclatura que visava a sua diferenciação: «pobre»; "pobre de pedir»; "pobre de pedir pelas portas»; "pobre de pedir e cega»; "pobre e aleijada»; «pobre mendicante». Muitos dos que surgem com esta classificação tinham uma ocupação, mas que não era decerto suficiente para garantir a sua subsistência ou do agregado familiar.

Após um período de decréscimo, o número de internamentos registou um aumento significativo em 1877. Neste ano, acorreram ao hospital de Caminha 77 doentes. Tal facto poderá ser explicado, em larga medida, pelos acidentes que ocorreram durante a construção do caminho de ferro que atravessa várias localidades do concelho (Feijó, 1992, p. 153). Entre janeiro de 1877 e igual mês de 1878, entraram naquela instituição 39 sinistrados, sendo as fraturas, contusões e queimaduras as principais causas da sua hospitalização ${ }^{5}$. No caso dos operários mais velhos, o esforço físico que Ihes era exigido agravava as mazelas associadas ao exercício da profissão. Assim se explica que o reumatismo fosse também um dos motivos que levava vários trabalhadores a procurarem os serviços hospitalares ${ }^{6}$. Entre os internados, além de portugueses originários do concelho e de terras mais longínquas, designadamente de Mesão Frio, Leiria, Celorico da Beira e São João da Pesqueira, havia alguns de nacionalidade espanhola, provenientes sobretudo da Galiza. Só em 1877 foram hospitalizados 18 trabalhadores galegos ${ }^{7}$.

A área de intervenção do hospital abrangia sobretudo as populações do concelho de Caminha, embora acolhesse também enfermos procedentes de outros lugares. Entre os não naturais, destacavam-se os galegos, cujo número superava o de pacientes de concelhos próximos que integram o distrito de Viana do Castelo, como Monção, Melgaço, Ponte de Lima, Arcos de Valdevez ou Ponte da Barca.

A presença de galegos, em número apreciável, resultava, desde logo, da proximidade geográfica com a província da Galiza. Eram vários os motivos que os traziam a Portugal: uns procuravam trabalho, outros fugiam ao serviço militar ou às malhas da justiça, outros ainda vinham simplesmente mendigar (Fernández Cortizo, 2006, pp. 41-58; Alves, 2002, pp. 117-126; Durães, 2006, pp. 133-150). Assim, muitos dos que procuravam o hospital da Misericórdia eram pobres. A maioria residia no concelho de Caminha, outros estavam só de passagem. Era este o caso de João António Rodrigues, um aguadeiro, natural de Pontevedra, que, vindo de Lisboa, não suportou a longa jornada até ao Norte. Doente e muito debilitado, recorreu ao hospital de Caminha, onde veio a falecer ${ }^{8}$.

Na década de 40, numa altura em que o Alto Minho viveu momentos conturbados, que exigiram a in- 
tervenção das forças militares, foi elevado o número de soldados internados. Tal como as grandes obras ou os trabalhos sazonais, também as movimentações do exército arrastavam indivíduos oriundos das mais diversas regiões do país, o que se refletia, ainda que momentaneamente, na população hospitalar, aquando da sua passagem por uma determinada localidade. Assim acontecia em Caminha. No que diz respeito às razões que levavam os soldados ao hospital, apenas as conhecemos a partir da década de 60 (Gómez Rodríguez, 1991, pp. 292-305; Ramos Martínez, 1989, pp. 367-377). Mais do que as ações bélicas, eram maleitas diversas, como o reumatismo, a gastroepatite ou a supressão de transpiração, que os forçavam a procurar cuidados médicos ${ }^{9}$. Os soldados, tal como os guardas-fiscais e marinheiros, tinham que pagar o seu internamento.

Os irmãos da Santa Casa da vila tinham prioridade no acesso ao hospital de Nossa Senhora da Visitação, ao passo que os doentes portadores de enfermidades contagiosas e crónicas, nomeadamente os tinhosos, os sifilíticos e os tuberculosos, não eram admitidos. Tratava-se de moléstias que, ao longo do século XIX e, inclusive, no século $X X$, continuavam a assumir uma dimensão epidémica. Também não eram aceites os estrangeiros que não tivessem morada estabelecida no concelho de Caminha, que não apresentassem documento comprovativo da gravidade da enfermidade ou que, se não houvesse risco imediato para a sua saúde, pudessem ser transferidos para o hospital das terras de origem.

\section{O QUOTIDIANO HOSPITALAR}

A unidade hospitalar era constituída por duas enfermarias, mas desconhecemos se existia numerus clausus nas entradas, uma vez que os seus estatutos apenas referem que o número de pacientes admitidos devia ser regulado de acordo com a capacidade financeira da instituição ${ }^{10}$.

Os doentes menos abastados que pretendessem ingressar no hospital tinham que dirigir um requerimento ao provedor da Santa Casa da Misericórdia de Caminha. Geralmente, os peticionários, além da doença, invocavam a pobreza para justificar o seu pedido. 0 hospital também dispunha de quartos particulares para os mais endinheirados. Em 1877, segundo o disposto no regulamento da instituição, os doentes que quisessem permanecer nas enfermarias gerais teriam de desembolsar 240 réis por dia. Se, durante a estadia, pretendessem que Ihes fosse servido vinho maduro, acresciam 60 réis ao valor inicial. Caso optassem por quartos particulares, pagariam diariamente 400 réis. Se o regime alimentar incluísse vinho maduro, assados e comida distinta da dos restantes doentes, então o montante ascendia aos 600 réis. Na eventua- lidade de desejarem usufruir da enfermaria privativa, a quota diária atingia os 1000 réis $^{11}$.

Os doentes que não estivessem em condições de se dirigirem ao hospital pelos próprios meios seriam visitados pelo médico da instituição, que se encarregava de verificar a necessidade de ser utilizada a maca ou a cadeirinha para os transportar ${ }^{12}$. Por norma, os doentes eram tratados por um único médico e apenas em casos excecionais o hospital recorria aos serviços de outro facultativo.

A ordem e o silêncio, bem como o horário de admissão de doentes, das refeições e visitas, deviam ser escrupulosamente respeitados. Havia um controlo muito apertado sobre as pessoas estranhas ao hospital, para impedir qualquer ocorrência que perturbasse o seu normal funcionamento. Julgamos, no entanto, que esta vigilância também visava impedir a saída indevida de géneros alimentares, substâncias medicamentosas e outros produtos destinados aos doentes. Aliás, os furtos praticados na instituição ocorriam com alguma frequência. Os autores destes atos, quando identificados, podiam ser entregues à autoridade administrativa ${ }^{13}$

O mordomo do mês liderava o governo do hospital. Cabia-lhe, entre outras funções, controlar as visitas, fiscalizar diariamente a qualidade das rações de pão e carne e outros alimentos distribuídos aos doentes, visitar as enfermeiras várias vezes ao dia, inquirir os doentes sobre o modo como eram tratados, ouvir as suas queixas e tentar avaliar a sua relação com os empregados com o intuito de verificar se aqueles partilhavam com estes a sua ração, ou se a vendiam ${ }^{14}$. Competia-Ihe ainda cuidar da inspeção sanitária do hospital, averiguando se as regras de higiene eram respeitadas, tratar da compra dos produtos necessários, avaliar se o doente podia suportar as despesas do seu curativo e proceder, mensalmente, à venda dos espólios ${ }^{15}$.

As visitas aos enfermos, por familiares e amigos próximos, apenas tinham lugar duas vezes na semana, aos domingos e à quinta-feira, não devendo exceder a meia hora. As únicas exceções eram os acidentados, cujos familiares podiam entrar a qualquer momento no hospital. A partir das oito horas da noite até ao amanhecer, o silêncio era a palavra de ordem, o que denota a importância que era atribuída ao repouso dos doentes.

Os funcionários do hospital deviam respeitar um conjunto de normas no exercício das suas funções, em nome da ordem e da disciplina: não podiam falar alto, fumar, estar à janela, nem usar chapéu, roupas sujas ou tamancos. Os doentes, por seu lado, também tinham certos deveres a cumprir: não podiam recusar o alimento que lhes era prescrito e que fazia parte 
do seu tratamento, usar roupas indecorosas, erguer a voz, infringir qualquer ordem médica, como sair da cama sem autorização, faltar ao respeito aos outros pacientes ou pedir esmola aos visitantes ${ }^{16}$ (Castro, 2008, pp. 621-633). A necessidade de manter a ordem e o sossego era também um pretexto para que o internamento de doentes mentais não fosse bem visto. Em caso de incumprimento das regras estabelecidas, o infrator começava por ser repreendido, mas se houvesse reincidência havia lugar à aplicação de sanções, que podiam consistir na redução da ração ou na colocação no isolamento ${ }^{17}$. Para as situações mais graves estava prevista a expulsão ${ }^{18}$.

Encontrámos no hospital de Caminha claras preocupações com o asseio e a higienização das instalações. Aquando da sua admissão, o doente, especialmente o pobre, devia tomar um banho e as suas roupas eram lavadas. Diariamente, as enfermarias eram limpas e as latrinas desinfetadas. Anualmente, o hospital era caiado e a palha das camas era renovada ${ }^{19}$. Caso se verificasse o ingresso de um doente portador de mal contagioso, os cuidados com a salubridade eram ainda mais rigorosos.

No ideário português oitocentista, o trabalho continuava a funcionar como uma espécie de lenitivo num quotidiano marcado pela doença, mas onde não havia lugar para a ociosidade. Por isso mesmo, os indivíduos que se encontrassem em asilos ou nas prisões e até mesmo os que estavam temporariamente arredados da vivência pública por motivos de saúde, deviam ocupar o espírito com um ofício. Assim, segundo o regulamento do hospital do Caminha, os doentes convalescentes poderiam trabalhar até quatro horas por dia, executando tarefas leves, como, por exemplo, consertar peças de roupa pertencentes à instituição ${ }^{20}$.

Ao pessoal hospitalar estavam atribuídas tarefas específicas, de modo a assegurar o bom funcionamento e a qualidade do serviço. Assim, ao diretor clínico cabia visitar diariamente os doentes e tratá-los com afeto, prescrever as substâncias medicamentosas para o seu tratamento e convocar a Junta quando surgisse uma doença mais grave. O farmacêutico estava incumbido de fornecer, com a maior celeridade e a qualquer hora do dia, os remédios que fossem necessários $^{21}$ (Araújo, 2010, pp. 35-52). Ao capelão mor competia zelar pelo apoio espiritual do doente através da confissão e da administração dos sacramentos, devendo estar sempre disponível para acudir aos moribundos $^{22}$ (Araújo, 2000, p. 641). A hospitaleira estava encarregada de organizar a vida do hospital de acordo com as orientações do mordomo e do diretor clínico, zelar pela limpeza de louças, talheres, panelas e do fogão, acompanhar o clínico nas visitas aos enfermos e ministrar-lhes as refeições, bem como higienizar os instrumentos utilizados nas cirurgias, entre muitas outras funções ${ }^{23}$. Devia ser conciliadora com os empregados, atenciosa com as visitas, caridosa com os doentes pobres e respeitosa com os irmãos da Misericórdia ${ }^{24}$. O enfermeiro menor, entre outros encargos, era o responsável pela higienização das instalações e pela administração dos medicamentos prescritos pelo médico ou pela enfermeira. À cozinheira competia preparar as refeições, seguindo as orientações da hospitaleira, e tratar da aquisição dos produtos necessários para a sua confeção ${ }^{25}$.

Em finais do século XIX, a Santa Casa da Misericórdia de Caminha passava cartas de guia aos doentes do seu hospital e residentes no concelho que, devido à sua patologia e com fins profiláticos, necessitassem de banhos termais, ou que, pelos mesmos motivos, precisassem de receber cuidados noutras unidades hospitalares, nomeadamente nas das terras de origem $^{26}$. Em todos os casos, o beneficiário, para além do transporte, recebia uma esmola nunca inferior a 500 réis. O hospital prestava apoio aos peregrinos e àqueles que deslocavam para a vila de Caminha para usufruírem dos banhos de mar, dando-lhes dormida nas suas instalações ${ }^{27}$.

\section{OS DOENTES}

No século XIX, Caminha era um concelho essencialmente agrícola e piscatório, não sendo de estranhar que, entre os que receberam assistência hospitalar, predominassem pessoas ligadas ao trabalho da terra e à faina do mar, além de gente dos ofícios, nomeadamente sapateiros, pedreiros e carpinteiros.

Entre os internados, sobressai o número de homens e mulheres que trabalhavam à jorna. $O$ jornaleiro era um trabalhador assalariado, sem lugar fixo, sujeito à sazonalidade dos afazeres agrícolas e aos caprichos dos patrões, que nem sempre se dispunham a retribuir condignamente os serviços prestados ${ }^{28}$ (Carasa Soto, 1985, p. 172). Era elevado o número de jornaleiras que acorria ao hospital de Caminha, na sua maioria solteiras. Muitas destas mulheres viviam sozinhas, circunstância que muito contribuiria para a sua indigência. Importa sublinhar que o concelho de Caminha se insere numa região onde, na altura, se verificava uma forte corrente migratória da população masculina, que tinha o Brasil como principal destino. Por isso, a solidão não afetava apenas as mulheres solteiras ou viúvas, mas igualmente as casadas, sobre as quais recaía a responsabilidade pela conservação e gestão do património familiar (Rodrigues, 1995). Num quadro de penúria, que atingia sobretudo as gentes do campo, onde escasseavam o alimento, o vestuário e a limpeza, abundava o terreno fértil para a doença.

Além das mulheres que se dedicavam ao trabalho agrícola, o hospital recebia criadas de servir, costureiras, padeiras, entre outras. As terras de origem das 
serviçais eram as mais variadas. Se a maioria pertencia ao concelho de Caminha, outras provinham do Porto, Braga, Penafiel, Arcos de Valdevez, Monção ou da vizinha província espanhola da Galiza. Enquanto as jornaleiras se destacavam pela idade avançada, a maioria das criadas eram raparigas jovens ou até, em alguns casos, ainda crianças. Importa referir, a este propósito, que, no momento do internamento, muitas crianças davam conta do ofício que já exerciam: criado de servir, alfaiate, pescador, embarcadiço, ou então assumiam o estatuto de mendigos.

A comunidade piscatória, de que é exemplo a que existia na freguesia de Seixas, no concelho de Caminha, também não conseguia escapar à indigência. Os pescadores aparecem mencionados como gente pobre, cuja situação se agravou na sequência do motim que ocorreu em dezembro de 1854, no distrito de Viana do Castelo, motivado pela carestia de alimentos que então se fez sentir ${ }^{29}$.

Para além daqueles que surgem classificados como pobres, encontrámos ainda doentes, sobretudo muIheres, que sobreviviam à custa da mendicidade. Quase todas ultrapassavam a faixa etária dos 30 anos de idade e, nos casos em que é disponibilizada informação sobre o estado civil, a larga maioria era solteira, seguindo-se, em percentagem mais reduzida, as viúvas e as casadas. Tais dados evidenciam a conexão entre a solidão feminina e a pobreza.

Os mendigos eram os mais pobres de todos os pobres, dispondo apenas da esmola para sobreviver. Por vezes, dirigiam-se ao hospital, não só em busca de cura para os males de que padeciam, mas também para obterem comida, cuidados de higiene e algum conforto. Muitos deles não dispunham sequer de roupa suficiente para se resguardarem do frio e da chuva, de alimento para nutrir os corpos ou do abrigo de uma casa. Por isso, estavam mais expostos a todo o tipo de doenças, que os obrigava a recorrer com frequência à assistência hospitalar, até que a morte pusesse fim ao seu calvário.

Dada a vida errante que levavam, os mendigos doentes podiam representar um perigo para a saúde pública, pelo que o seu internamento era tido como recomendável. O facto de, nas fontes, aparecerem classificados como pedintes indicia que se tratava de verdadeiros pobres e não de vadios. Àqueles era atribuída uma licença para mendigar, cuja validade se circunscrevia aos limites do concelho de residência, o que, em certa medida, condicionava os seus movimentos. Cabia ao administrador do concelho a vigilância sobre mendigos e vagabundos. Ainda no século XVIII, acreditava-se que os pedintes estavam entre os responsáveis pela propagação de enfermidades, suspeita que se alargou a toda a população pobre a partir de oitocentos, com o surgimento de surtos epidémi- cos, como a cólera e a febre-amarela (Relvas, 2002, pp. 81-83). Daí que todos os seus comportamentos e hábitos passassem a ser alvo da desconfiança dos estratos sociais mais abastados, que apostavam na sua moralização através da aplicação do conceito de higiene nos domínios da habitação, do vestuário, do corpo e até dos costumes.

\section{AS DOENÇAS}

As privações alimentares, a ausência de limpeza e de conforto das habitações, o desconhecimento dos hábitos de higiene privada, entre outras carências que afetavam a maior parte da população, constituem os fatores explicativos da maioria das enfermidades diagnosticadas, sobretudo do foro respiratório, gastrointestinal e dermatológico, que obrigavam os pacientes a recorrerem ao hospital de Caminha. A tinha, por exemplo, era uma doença dermatológica que atingia principalmente as crianças e que estava associada à falta de higiene pessoal e habitacional, um problema que continuava a atingir as populações no decorrer de oitocentos e nas primeiras décadas da centúria seguinte (Araújo, 2008b, pp. 135-149, pp. 141-146; Pardal, Rute 2007, pp. 757-766). Ainda no início do século XX, a casa do Alto Minho era descrita com um espaço pouco arejado e desprovido de qualquer comodidade, que não protegia os moradores do frio nem das intempéries, que albergava pessoas e animais e donde emanavam cheiros nauseabundos provocados pela acumulação de dejetos (Leal, 2000, pp. 152-153; Cascão, 2011, pp. 22-55, pp. 34-35). As febres, de várias origens, na maior parte das vezes indeterminadas, constavam do rol de motivos que justificavam o tratamento hospitalar. A ausência de conhecimentos médicos mais aprofundados pode explicar a dificuldade em precisar a causa dos estados fabris, se bem que as razões mais frequentes fossem a "gástrica» e a «inflamatória».

No registo de entrada dos doentes, raramente se apontava a patologia ou o sintoma que tinham justificado a ida ao hospital. Face à ausência de instituições vocacionadas para o tratamento de determinadas moléstias, designadamente as contagiosas, todos os enfermos, independentemente dos males de que padeciam, acabavam por recorrer aos hospitais gerais, que, por isso, acolhiam uma população muito heterogénea. Esta circunstância colocava em risco a saúde pública, além de tornar o ambiente hospitalar propício à propagação de doenças. Conseguimos apurar o ingresso de doentes portadores de moléstias endémicas, como a sífilis, a varíola e a já referida tísica. Apesar de esta última ter atingido grandes proporções na centúria de oitocentos, foi necessário esperar pelo século XX para que a região dispusesse de um estabelecimento destinado ao tratamento da tuberculose. De facto, em 1929, em Viana do Cas- 
telo, abriu portas o Hospital Padre Luís Faria, para doentes com tuberculose pulmonar. Anos antes, mas apenas na primeira década de novecentos, entrou em funcionamento um sanatório marítimo, em Vila Praia de Âncora, no concelho de Caminha, mas direcionado para o tratamento da tuberculose óssea. Assim, apesar das limitações de espaço, o hospital de Caminha, como outras instituições congéneres, via-se compelido a acolher todo o tipo de pacientes.

A inexistência de hospitais vocacionados para o acoIhimento de doentes mentais nesta região de Portugal também explica o seu internamento nos hospitais gerais, bem como a sua permanência no espaço doméstico ou o seu envio para os cárceres. A criação do Hospital de Rilhafoles em Lisboa, em 1848, e, mais tarde, do Hospital Conde Ferreira, na cidade do Porto, não resolveu o problema da assistência a estes doentes, uma vez que, desde a sua abertura, estas instituições debateram-se com múltiplas dificuldades, em particular a sobrelotação. Nos hospitais gerais, os doentes mentais decerto que usufruíam de um conforto maior do que o proporcionado pelos cárceres. Todavia, a impreparação dos clínicos para lidarem com a enfermidade, as restrições do espaço e o estigma que os perseguia, entre outros condicionalismos, não ajudavam a melhorar o seu estado ${ }^{30}$. Importa referir que o Hospital de Nossa Senhora da Visitação, segundo o Regulamento Geral de 1877, não permitia a admissão de doentes mentais, a não ser que fosse solicitada por uma autoridade administrativa, que, no entanto, teria de assumir o compromisso de que a sua estadia seria breve e que, posteriormente, Ihes passaria guia para serem transferidos para outros estabelecimentos. No século XIX, os alienados eram persona non grata nos hospitais, situação resultante da incompreensão que persistia relativamente à doença mental e aos comportamentos a ela associados. A recusa e os condicionalismos impostos ao seu ingresso relacionavam-se com a necessidade de os hospitais precaverem o pessoal e as estruturas físicas das arremetidas intempestivas desses enfermos.

Dada a inexistência de enfermarias nas cadeias, os presos, quando acometidos por doenças mais graves, tinham que ser transportados para as instituições hospitalares. Nessas ocasiões, estes espaços tinham que reforçar as condições de segurança, dado que a estadia no hospital podia transformar-se numa oportunidade de fuga. Por isso, enquanto durasse o seu internamento, um guarda acompanhava permanentemente esses reclusos (Esteves, 2010, p. 672). Entre 1840 e 1878, o hospital de Caminha acolheu quinze detidos do estabelecimento prisional da vila. Porém, muitos outros eram tratados dentro das paredes do cárcere ${ }^{31}$. Atendendo à localização de muitas cadeias comarcãs na malha central dos povoados e do perigo que representavam para a saúde pública, foi decidido que, de acordo com a portaria de 17 de maio de 1850 , em todos os concelhos onde houvesse médico municipal, este seria responsável pelas visitas à prisão, que deveriam realizar-se duas vezes por semana, em dias incertos, e, se não houvesse médico municipal, essa função caberia ao cirurgião da Câmara. No entanto, o facto de os facultativos terem essa obrigação não significava que a cumprissem. Aquando da visita, o médico devia prescrever o tratamento adequado aos presos atacados por moléstias que podiam ser curadas dentro da cadeia, indicar aqueles que deviam ser transferidos para os hospitais e anotar as medidas higiénicas indispensáveis, que seriam requeridas junto do delegado do procurador régio.

Uma doença que se manifestou em todo o país na década de 60 do século XIX, cujas proporções ainda não foram devidamente averiguadas no Alto Minho, foi a febre tifoide. No hospital de Caminha, foi registado um caso (Roque, 2000, pp. 104-136). Tratava-se de uma enfermidade que, ao tempo, já se associava à insuficiência alimentar, à ausência de salubridade nos espaços domésticos e de cuidados de higiene pública e privada (Ujvari, 2003, pp. 71-77). Esta ligação tem fundamento, uma vez que o tifo resultava de um agente infecioso que se instalava no organismo do piolho, transmitindo-se ao ser humano através da sua picada. Dada a quase inexistência de hábitos de higiene pessoal, a presença de piolhos era comum nas cabeças e nos corpos sobretudo das classes mais desfavorecidas, o que poderia provocar verdadeiros surtos epidémicos. Aliás, os viajantes estrangeiros que visitavam Portugal nos séculos XVIII, XIX e inícios do século $X X$, espantavam-se com um dos costumes que ocupava uma parte do tempo do povo luso, que consistia precisamente em catar piolhos (Vicente, 2001, p. 174).

Outra epidemia que marcou o Portugal oitocentista e provocou vítimas em Caminha, desde a década de 60 , foi a varíola. Esta enfermidade, vulgarmente conhecida por "bexigas», era bastante frequente nesta época. Ainda no século XIX, assumia proporções de autêntico flagelo, atingindo sobretudo as crianças A partir dos registos hospitalares, descobrimos dois casos, um deles mortal ${ }^{32}$.

Sobressai, igualmente, a presença de um conjunto de sintomas associados à subalimentação, como, por exemplo, a fome e a extenuação de forças, e que, apesar de não serem característicos de uma doença em particular, fragilizavam as pessoas. Por essa razão, foram incluídos no referido quadro, uma vez que, se não fossem devidamente tratados, designadamente através do reforço da dieta alimentar, podiam provocar diversas enfermidades e até mesmo a norte (Resende, 2009, pp. 67-92, pp. 78-82). No entanto, aqueles indícios também podiam ser manifestações de moléstias ainda não devidamente diagnosticadas, como, por exemplo, de anemia. Todavia, os médicos interpretavam-nos como doenças, que procuravam tratar unicamente com o reforço da alimentação. 


\section{CONCLUSÃO}

Num tempo em que as populações estavam expostas a todo o tipo de enfermidades, muitas delas originadas e agravadas por carências diversas, designadamente a ausência de uma alimentação adequada, de hábitos de higiene, de lares com um mínimo de limpeza e de conforto, o hospital de Nossa Senhora da Visitação, de Caminha, servia de porto de abrigo para aliviar as doenças de que padeciam sobretudo os mais desfavorecidos.

\section{NOTAS}

1 Algumas das matérias aqui apresentadas já foram objeto de análise num outro trabalho que realizámos sobre a mesma instituição.

2 Arquivo Distrital de Viana do Castelo (doravante AHDV), Estatutos da Santa Real Casa de Caminha, 7.36.3.3.26.

3 Em Ponte de Lima, a Santa Casa também ajudava os doentes que não podiam ou não queriam ser internados no hospital, enviando-Ihes alimento, remédios ou ainda o médico ou cirurgião da instituição (Araújo, 2006, pp. 481-492). O mesmo se verificava no Hospital Real do Espírito Santo de Portel, estudado pela mesma autora (Araújo, 2003, pp. 341-498). Em Monção, a construção do hospital da Santa Casa só se concretizou em 1803. No entanto, a instituição prestava auxílio aos doentes, cuidando da sua cura, através dos serviços que prestava ao domicílio (Araújo, 2008a, p. 305). Também a Misericórdia de Ponte da Barca prestou este tipo de serviço (Pereira, 2008, p. 288).

4 Note-se que para o período compreendido entre 1856 e 1862 não dispomos de fontes arquivísticas. Desconhecemos as razões que justificam a sua inexistência.

5 ADVC, Santa Casa da Misericórdia de Caminha, Registo da entrada de doentes (1836-1878), n.o 7.35.4.10.

6 ADVC, Santa Casa da Misericórdia de Caminha, Registo da entrada de doentes (1836-1878), n.o 7.35.4.10, fl. 62.

7 ADVC, Santa Casa da Misericórdia de Caminha, Registo da entrada de doentes (1836-1878), n.o 7.35.4.10.

8 ADVC, Santa casa da Misericórdia de Caminha, Registo da entrada de doentes (1836-1878), n.o 7.35.4.10, fl. 46v.

9 ADVC, Santa Casa da Misericórdia de Caminha, Registo da entrada de doentes (1836-1878), n. 7.35.4.10.

10 ADVC, Estatutos da Santa Real Casa de Caminha, 7.36.3.3.26.

11 ADVC, Santa Casa da Misericórdia de Caminha, Regulamento Geral da administração da Santa casa da Misericórdia de Caminha, n.o 7.36.3.3-22, fl. 16v.

12 ADVC, Santa Casa da Misericórdia de Caminha, Regulamento Geral da administração da Santa casa da Misericórdia de Caminha, n.은 7.36.3.3-22, fl. 14.
Analisado o espaço, os utentes, mais ou menos temporários, e cruzando estes dados com as regras referentes ao hospital de Nossa Senhora da Visitação, constantes do Regulamento Geral da Administração da Santa Casa da Misericórdia, datado de 1877, verificamos que, a par da preocupação em proporcionar aos doentes a cura para os males que os afligiam, havia também uma clara intenção de levar aquela instituição a adotar e cumprir os princípios defendidos pelo discurso higienista da época, cuja aplicação, em Portugal, se tornou mais urgente na sequência dos surtos epidémicos que marcaram a centúria de oitocentos.

13 ADVC, Santa Casa da Misericórdia de Caminha, Regulamento Geral da administração da Santa casa da Misericórdia de Caminha, n.o 7.36.3.3-22.

14 ADVC, Santa Casa da Misericórdia de Caminha, Regulamento Geral da administração da Santa casa da Misericórdia de Caminha, n. ․36.3.3-22, fl. 17v.

15 ADVC, Santa Casa da Misericórdia de Caminha, Regulamento Geral da administração da Santa casa da Misericórdia de Caminha, n.o 7.36.3.3-22, fl. 18

16 ADVC, Santa Casa da Misericórdia de Caminha, Regulamento Geral da administração da Santa casa da Misericórdia de Caminha, n.o 7.36.3.3-22, fl. 15 .

17 ADVC, Santa Casa da Misericórdia de Caminha, Regulamento Geral da administração da Santa casa da Misericórdia de Caminha, n.o 7.36.3.3-22, fl. 15

18 ADVC, Santa Casa da Misericórdia de Caminha, Regulamento Geral da administração da Santa casa da Misericórdia de Caminha, n.o 7.36.3.3-22 fl. 15 v.

19 ADVC, Santa Casa da Misericórdia de Caminha, Regulamento Geral da administração da Santa casa da Misericórdia de Caminha, n.o 7.36.3.3-22, fl. 17.

20 ADVC, Santa Casa da Misericórdia de Caminha, Regulamento Geral da administração da Santa casa da Misericórdia de Caminha, n.o 7.36.3.3-22, fl. $15 \mathrm{v}$.

21 Quando o hospital não dispunha de farmácia, os remédios eram preparados numa botica e, posteriormente, transportados para o espaço hospitalar.

22 ADVC, Santa Casa da Misericórdia de Caminha, Regulamento Geral da administração da Santa casa da Misericórdia de Caminha, n.o 7.36.3.3-22, fl. 18v.

23 ADVC, Santa Casa da Misericórdia de Caminha, Regulamento Geral da administração da Santa casa da Misericórdia de Caminha, n. 7.36.3.3-22, fl. 20.

24 ADVC, Santa Casa da Misericórdia de Caminha, Regulamento Geral da administração da Santa casa da Misericórdia de Caminha, n. 7.36.3.3-22, fl. 20. 
25 ADVC, Santa Casa da Misericórdia de Caminha, Regulamento Geral da administração da Santa casa da Misericórdia de Caminha, n.o 7.36.3.3-22, fl. 21.

26 ADVC, Santa Casa da Misericórdia de Caminha, Regulamento Geral da administração da Santa casa da Misericórdia de Caminha, n. 7.36.3.3-22, fl. 12.

27 ADVC, Santa Casa da Misericórdia de Caminha, Regulamento Geral da administração da Santa casa da Misericórdia de Caminha, n. ․36.3.3-22, fl. 12

28 No hospital de Cabeceiras de Basto, entre os finais do século XIX e os primórdios do século XX, predominavam, entre a clientela hospitalar, os jornaleiros (Ferraz, 2008, pp. 237-259,

\section{REFERÊNCIAS BIBLIOGRÁFICAS}

Alves, Jorge Fernandes (2002), "Imigração de galegos no Norte de Portugal (1500-1900)". Em: Eiras Roel, Antonio y Domingo González Lopo (coord.), Movilidad e migrácions internas na Europa latina, Santiago de Compostela, Unesco, pp. 117-126.

Araújo, Maria Marta Lobo de (2000), Dar aos pobres e emprestar a Deus: as Misericórdias de Vila Viçosa e Ponte de Lima (séculos XVI-XVIII), Barcelos, Santa Casa da Misericórdia de Vila Viçosa e Ponte de Lima.

Araújo, Maria Marta Lobo de (2003), “O hospital do Espírito Santo de Portel na Época Moderna", Cadernos do Noroeste, Série História 3, 20, (1-2), pp. 341-498.

Araújo, Maria Marta Lobo de (2005), "Misericórdia de Caminha". Em: Capela, José Viriato (coord.), As freguesias do distrito de Viana do Castelo nas Memórias Paroquiais de 1758. Alto Minho: Memória, História e Património, Braga, Casa Museu de Monção, Universidade do Minho, pp. 668-669.

Araújo, Maria Marta Lobo de (2006), "Os hospitais de Ponte de Lima na era pré-industrial", Separata do livro Atas do século XVIII Seminário Internacional sobre Participação, Saúde e Solidariedade - Riscos e Desafios, Braga, ICS, pp. 481-492.

Araújo, Maria Marta Lobo de (2008a), A Misericórdia de Monção: fronteira, guerras e caridade (1561-1810), Braga, Misericórdia de Monção.

Araújo, Maria Marta Lobo de (2008b), "Pequenos e pobres: a assistência nas Misericórdias portuguesas da Idade Moderna". Em: Araújo, Maria Marta Lobo de; Maria de Fátima Ferreira (Orgs.), A infância no universo assistencial da Península Ibérica (sécs. XVI-XIX), Braga, Instituto de Ciências Sociais, pp. 135-149.

Araújo, Maria Marta Lobo de (2010), A Misericórdia de Vila Viçosa de finais do Antigo Regime à República, Braga, Santa Casa da Misericórdia de Vila Viçosa.

Araújo, Maria Marta Lobo de y Alexandra Esteves (2010), "Healing the Body and Saving the Soul in the Portuguese Hospitals of the Early Modern Age", Hygiea Internationalis: An Interdisciplinary Journal for the History of Public Health, 9 (1), pp. 35-52. pp. 238-240). O mesmo se verificava no hospital de Burgos (Carasa Soto, 1987, pp. 218-219).

29 ADVC, Confidencial geral - de outubro de 1848 a outubro de 1855, n.o 1.9.3.29, não paginado.

30 ADVC, Santa Casa da Misericórdia de Caminha, Registo da entrada de doentes (1836-1878), n.o 7.35.4.10, fl. 49v.

31 ADVC, Santa Casa da Misericórdia de Viana do Castelo, Registo da entrada de doentes (1836-1878), n.o 7.35.4.10.

32 ADVC, Santa Casa da Misericórdia de Caminha, Registo da entrada de doentes (1836-1878), n.o 7.35.4.10, fl. 44, 42.

Carasa Soto, Pedro (1985), El sistema hospitalario español en el siglo XIX. De la asistencia benéfica al modelo sanitário atual, Universidad de Valladolid, Caja de Ahorros y Monte de Piedad de Salamanca.

Carasa Soto, Pedro (1987), Pauperismo y Revolucion burguesa (Burgos 1750-1900), Universidad de Valladolid.

Cascão, Rui (2011), "Modos de habitar". Em: Vaquinhas, Irene, História da Vida Privada em Portugal. A época contemporânea, Lisboa, Círculo de Leitores, 2011, pp. 22-55.

Castro, Maria de Fátima (2008), A Misericórdia de Braga. A Assistência no Hospital de S. Marcos, vol. IV. Santa Casa da Misericórdia de Braga.

Durães, Margarida (2006), "As mulheres estrangeiras no noroeste de Portugal: imigrações femininas galegas do ponto de vista português (Sécs. XIX-XX)". En: Hérnandez Borge, Julio y Domingo L. González Lopo (Edits.), Atas del Colóquio Internacional Cátedra Unesco 226 sobre Migracións, Santiago de Compostela, Universidade de Santiago de Compostela Publicacións, pp. 133-150.

Esteves, Alexandra Patrícia Lopes (2010), Entre o crime e a cadeia: Violência e marginalidade no Alto Minho (1732-1870), Tese de doutoramento policopiada. Braga, Universidade do Minho.

Feijó, Rui Graça (1992), Liberalismo e Transformação Social. A Região de Viana do Antigo Regime a finais do Liberalismo, Lisboa, Fragmentos.

Fernández Cortizo, Camilo (2006), "La emigración gallega a las províncias portuguesas del Miño y de Trás-os-Montes y Alto Duero durante el siglo XVIII y la primera mitad del XIX". En: Congresso Internacional de História. Territórios, Culturas e Poderes. Atas, vol. I, Braga, Núcleo de Estudos Históricos, Universidade do Minho, pp. 41-58.

Ferraz, Norberto Tiago Gonçalvez (2008), "O tratamento de doentes no hospital de Cabeceiras de Basto", Estudos Humanísticos. História, 7, pp. 237-259. 
Gómez Rodríguez, Maria Soledad (1991), El Hospital de la Misericordia de Toledo en el siglo XIX, Tese de doutoramento policopiada. Universidad Complutense de Madrid, pp. 292-305.

Leal, João (2000), Etnografias Portuguesas (1870-1970). Cultura Popular e Identidade Nacional, Lisboa, Publicações Dom Quixote.

Lopes, Maria Antónia (2000), Pobreza, Assistência e Controle Social. Coimbra (1750-1850), vol. 1. Viseu, Palimage Editores.

Pardal, Rute (2007), "A Criação dos filhos dos pobres e dos tinhosos: um aspeto esquecido da assistência da Misericórdia de Évora no século XVIII", Congresso Internacional de História. Territórios, Culturas e Poderes, Atas, vol. II. Braga, Núcleo de Estudos Históricos, Universidade do Minho, pp. 757-766.

Pereira, Maria das Dores de Sousa (2008), Entre Ricos e Pobres: a atuação da Santa Casa da Misericórdia de Ponte da Barca (16301800), Braga, Santa Casa da Misericórdia de Ponte da Barca.

Ramos Martínez, Jesús (1989), La Salud Pública y el Hospital de la Ciudad de Pamplona en el Antiguo Régimen (1700-1815). Pamplona, Gobierno de Navarra.
Relvas, Eunice (2002), Esmola e degredo. Mendigos e Vadios em Lisboa (1835-1910), Lisboa, Livros Horizonte.

Resende, Maria Leônia Chaves de y Natália Silveira (2009), “Misericórdias da Santa Casa: um estudo de caso das práticas médicas nas Minas Gerais Oitocentistas". Em: Araújo, Maria Marta Lobo de (Org.), As Misericórdias das duas margens do Atlântico: Portugal e Brasil (séculos XV-XX), São Paulo, Carlini e Camiato, pp. 67-92.

Rodrigues, Henrique (1995), Emigração e Alfabetização. O Alto Minho e a Miragem do Brasil, Governo Civil de Viana do Castelo.

Roque, João Lourenço (2000), "Epidemias no distrito de Coimbra no Século XIX", Separata da Revista Portuguesa de História, Tomo XXXIV, pp. 1-152.

Vicente, Ana (2001), As Mulheres Portuguesas vistas por Viajantes estrangeiros (séculos XVIII, XIX e XX), Lisboa, Gótica.

Ujvari, Stefan Cunha (2003), A História e suas Epidemias. A convivência do homem com os microrganismos, Rio de Janeiro, Editora Senac Rio, Editora Senac São Paulo. 